\title{
Applications of Polymers in the Biomedical Field
}

\author{
Ibrahim ID ${ }^{1 *}$, Sadiku ER ${ }^{2}$, Jamiru T ${ }^{1}$, Hamam $\mathrm{A}^{3}$ and Kupolati $\mathrm{WK}^{4}$ \\ ${ }^{1}$ Department of Mechanical Engineering, Tshwane University of Technology, South Africa \\ ${ }^{2}$ Department of Chemical, Tshwane University of Technology, South Africa \\ ${ }^{3}$ Department of Electrical Engineering, Tshwane University of Technology, South Africa \\ ${ }^{4}$ Department of Civil Engineering, Tshwane University of Technology, South Africa
}

Submission: March 2, 2017; Published: May 30, 2017

*Corresponding author: Ibrahim ID, Department of Mechanical Engineering, Tshwane University of Technology, Pretoria, South Africa, Email: ibrahimid@tut.ac.za, ibrahimidowu47@gmail.com

\begin{abstract}
Polymeric materials have found notable applications in the field of biomedical. This is due to their useful properties, such as: easy processing, lightweight and flexibility, high strength to weight, availability and recyclability. Polymers in biomedical applications are: nontoxic, biodegradable, biocompatible and meet the required specification for which they are intended because it has direct contact with the human body. Mechanical and physical properties can be improved by the inclusion of nanoparticles and the method of preparation.
\end{abstract}

Keywords: Biomedical; Mechanical properties; Polymer; Self-healing

\section{Introduction}

Polymer-based composites have attracted considerable interest in areas, such as: automobile, construction, electronics, packaging and aviation industries [1,2]. Another important area where polymers have been widely used is in biomedical applications [3-5]. In clinical applications, the most widely used materials are the natural and modified natural materials. Other materials that have found useful applications are: metals, glass, ceramics, synthetic polymers and composites. This generation of materials is used due to their mechanical properties (high strength, toughness, and ductility) [6]. One of the most widely used synthetic polymers is poly (lactic acid) (PLA), which was reported to have been introduced by Biscnoff and Walden in 1893 [7]. Other polymers used for biomedical applications due to their biocompatibility, controllable degradation rate and their degradation into non-toxic components, include natural polymers, such as polysaccharides or proteins and synthetic polymers, such as: poly(glycolic acid) (PGA), poly(hydroxyl butyrate) (PHB) and poly ( $\varepsilon$-caprolactone) (PCL) [8]. Polypropylene (PP), polyurethane (PU) and polyethylene (PE) have equally found useful importance in biomedical applications. Some other polymers that are soluble in water fpoly (vinyl alcohol) (PVA), poly (ethylene glycol) (PEG), poly (vinyl acetate), poly (acrylic acid) (PAA) and guar gum $\}$, have also been used for similar applications [8].

\section{Desired Properties for Biomedical Application}

The level of safety of materials used in biomedical applications are taken seriously because they have direct interaction or contact with the human body; for these reasons, it must be non-toxic, biodegradable, biocompatible and meet the required specification for which it will be used. Three of the basic properties which are found in nature that are required of bio composite materials in order for it to be fit for biomedical application are: super hydro phobicity, adhesion and selfhealing. Several research works are on-going trying in order to develop materials that will meet all the requirements mentioned above.

\section{Super hydro phobicity}

Materials with super hydro phobic surfaces are known to be very tough to wet. This property is mostly exhibited by many insects and plants. The super hydro phobic property of biomaterials makes them useful in biomedical applications because they reduce the chances of blood coagulation as a result of unfavorable platelet adhesion [9]. Several biomaterials exhibiting this property have been produced [10].

\section{Adhesion}

This is another phenomenon that is exhibited by plants and animals, as it is also essential for organisms to survive. 
This helps organisms to attach themselves either permanently or temporally to their host or vice versa. Many ways in which adhesion abilities are important and used by bacteria, animals and plants are explained by Bassas-Galia et at. [9]. Polymeric materials with this property have been developed and used in biomedical applications, as explained by Bassas-Galia et at. [9].

\section{Self-healing}

The human body is engineered is in such a way that whenever there is an injury, it repairs and/or replace the damaged tissues; this is known as self-healing. This is possible if the portion of the injury is not too great. Whenever the injury or damage is beyond self-healing, there is a need for the introduction of alternative 'material', which can be in form of an implant. Implants are subjected to load, wear and aging, just to name a few, which can result in failure and will need to be replaced. These have necessitated researchers to try to produce materials that can self-heal. The first generation of self-healing biomaterials comprises of composites that are irreversibly repaired without restoring the damaged matrix, while the second generation reversibly restores the damaged matrix. Various polymers and their composites have been largely used due their merits and ability to handle the disadvantages associated with the polymer matrix. Self-healing materials $[10,11]$ should have the following characteristics:

a. Ability to heal the damaged portion of materials several times

b. Ability to automatically heal the materials

c. Ability to heal the materials with defects of any size

d. Reduced maintenance cost

e. In comparison with the traditional materials, it must exhibit equal or better performance

f. Should be economical than the materials already in use

In order to improve the mechanical and physical properties of polymeric-based self-healing materials, nanoparticles have been employed. Polymers have lower strength and modulus when compared to metals and ceramics, which is the reason that necessitates for the improvement.

\section{Improvement of Polymers for Biomedical Applications}

Polymer-based composites have been widely used for different applications due to their basic characteristics, which include: easy processing, lightweight and flexibility, high strength to weight, availability and recyclability; just to mention a few [12]. However, metals and ceramics exhibit better mechanical properties than polymer, which have led to the need for improvement in polymer properties. The improvement could be by blending with another polymer, incorporation of fibres and nano particle inclusion [13]. The incorporation of nanoparticles in a polymer matrix has resulted in novel and smart materials that have outstanding properties. Deka et al. [14] reported that 2.5 and $5 \mathrm{wt} \%$ of silver (Ag) nano particle incorporated into biocompatible hyper branched and linear polyurethane, significantly improved the impact resistance, Shore A hardness and tensile strength. Other metal nanoparticles that are mostly used for the same purpose include gold $(\mathrm{Au})$, copper $(\mathrm{Cu})$, platinum (Pt), palladium (Pd) and titanium (Ti), due to their biological, chemical and physical properties [8]. The method of preparation is another important route of improving the composite properties. The most common methods of preparation of polymer composites include: solution casting, electro spinning, compression moulding, injection moulding and resin transfer mould (RTM). Among all these methods, compression moulding is the oldest, while RTM has higher chances of eliminating voids within the composites, thereby resulting into better mechanical properties.

\section{Conclusion}

The merits of polymers have greatly influenced the significant attraction that has been witnessed especially in biomedical applications. Basic properties, such as: super hydro phobicity, adhesion and self-healing that are exhibited by plants and animals have been mimicked in some polymer matrices and have found useful applications in biomedical. Before polymeric materials can be used in biomedical applications, they must meet certain requirements, which include: non-toxic, biocompatibility and controllable degradation rate, because they have direct contact with the human body. The mechanical and physical properties of a polymeric matrix can be improved by the incorporation of nanoparticles, such as: $\mathrm{Ag}, \mathrm{Au}, \mathrm{Cu}, \mathrm{Pd}, \mathrm{Pt}$ and $\mathrm{Ti}$, at a controlled amount.

\section{Acknowledgment}

The fund provided by CSIR/DST IBS program, South Africa, is greatly appreciated.

\section{References}

1. Ibrahim ID, Jamiru T, Sadiku ER, Kupolati WK, Agwuncha SC, et al. (2016) Mechanical properties of sisal fibre-reinforced polymer composites: a review. Composite Interfaces 23(1): 15-36.

2. Fuchs ER, Field FR, Roth R, Kirchain RE (2008) Strategic materials selection in the automobile body: Economic opportunities for polymer composite design, Composites science and technology, 68:1989-2002.

3. Victor SP, Muthu J (2014) Bioactive mechanically favorable, and biodegradable copolymer nanocomposites for orthopedic applications. Mater Sci Eng C Mater Biol Appl 39: 150-160.

4. Ma Z, Mao Z, Gao C (2007) Surface modification and property analysis of biomedical polymers used for tissue engineering. Colloids Surf B Biointerfaces 60: 137-157.

5. Scognamiglio F, Travan A, Rustighi I, Tarchi P, Palmisano S, et al. (2016) Adhesive and sealant interfaces for general surgery applications, J Biomed Mater Res B Appl Biomater 104(3): 626-639.

6. Pertici G (2016) Introduction to bioresorbable polymers for biomedical, Bioresorbable Polymers for Biomedical Applications: From Fundamentals to Translational Medicine p. 1. 
7. Lin JH, Lu CT, He CH, Huang CC, Lou CW, et al. (2011) Preparation and evaluation of artificial bone complex material: chitosan/polylactic complex braids, Journal of Composite Materials, 45(19): 1945-1951.

8. Zare Y, Shabani I (2016) Polymer/metal nanocomposites for biomedical applications. Mater Sci Eng C Mater Biol Appl 60 195-203.

9. Bassas-Galia M, Follonier S, Pusnik M, Zinn M (2016) 2-Natural polymers: A source of inspiration, Bioresorbable Polymers for Biomedical Applications. Perale G Hilborn J Eds (2016): 31-64.

10. Mao C, Liang C, Luo W, Bao J, Shen J, et al. (2009) Preparation of lotusleaf-like polystyrene micro-and nanostructure films and its blood compatibility. Journal of Materials Chemistry 19(47): 9025-9029.

11. Thakur VK, Kessler MR (2015) Self-healing polymer nanocomposite materials: A review. Polymer 69 (2015): 369-383.
12. Ibrahim ID, Jamiru T, Sadiku RE, Kupolati WK, Agwuncha SC, et al. (2017) Dependency of the mechanical properties of sisal fiber reinforced recycled polypropylene composites on fiber surface treatment, fiber content and nanoclay, Journal of Polymers and the Environment 25(2): 427-434.

13. Ibrahim ID, Jamiru T, Sadiku ER, Kupolati WK, Agwuncha SC, et al. (2016) Impact of Surface Modification and Nanoparticle on Sisal Fiber Reinforced Polypropylene Nanocomposites. Journal of Nanotechnology, p. 6

14. Deka H, Karak N, Kalita RD, Buragohain AK (2010) Bio-based thermostable, biodegradable and biocompatible hyperbranched polyurethane/Ag nanocomposites with antimicrobial activity. Polymer Degradation and Stability 95: 1509-1517.

\section{Your next submission with Juniper Publishers will reach you the below assets}

- Quality Editorial service

- Swift Peer Review

- Reprints availability

- E-prints Service

- Manuscript Podcast for convenient understanding

- Global attainment for your research

- Manuscript accessibility in different formats

( Pdf, E-pub, Full Text, Audio)

- Unceasing customer service

Track the below URL for one-step submission https://juniperpublishers.com/online-submission.php 